\title{
Densidade populacional de Pratylenchus spp. em pastagens de Brachiaria spp. e sua influência na disponibilidade e na qualidade da forragem ${ }^{1}$
}

\author{
Cassia de Carvalho ${ }^{2}$, Celso Dornelas Fernandes ${ }^{3}$, Jaime Maia dos Santos ${ }^{4}$, Manuel Claudio Motta Macedo
}

\section{RESUMO}

Objetivando avaliar a densidade populacional de Pratylenchus brachyurus e Pratylenchus zeae, associados à Brachiaria brizantha, B. decumbens e B. humidicola, e sua influência na disponibilidade e na qualidade da forragem, realizou-se este trabalho. O experimento foi conduzido na Agropecuária Hisaeda, em Terenos, MS. Coletaram-se amostras de solo, raízes e parte aérea, em dez repetições ao acaso, de $1 \mathrm{~m}^{2}$ cada, dos seguintes tratamentos: Bom, Intermediário e Ruim, caracterizados visualmente, considerando-se a percentagem de material verde das plantas. As densidades de $P$. brachyurus e $P$. zeae foram avaliadas nas amostras de solo e raízes. Na parte aérea, avaliou-se a disponibilidade de matéria seca dos materiais verde, morto e da rebrota, estado nutricional das plantas e qualidade da forragem. A fertilidade do solo foi determinada em todas as unidades amostrais. Ambos os nematoides foram identificados em todas as amostras, com maior número nas raízes (entre 87-311 P. brachyurus e 1-61 P. zeae.10 g-1) que no solo (de 0-8 P. brachyurus a 1-39 P. zeae.200 $\mathrm{cm}^{-3}$ ), no entanto, não houve diferenças significativas, na quantidade de espécimes, entre os tratamentos. Considerando-se que essas forrageiras são perenes e hospedam Pratylenchus spp., há tendência ao aumento da população desses patógenos, ao longo do tempo, podendo se tornar um sério problema fitossanitário.

Palavras-chave: Brachiaria brizantha, B. decumbens, B. humidicola, Poaceae, Pratylenchus brachyurus, P. zeae.

\section{ABSTRACT}

\section{Population density of Pratylenchus spp. in pastures of Brachiaria spp. and its influence on the forage availability and quality}

The aim of this work was to evaluate the population density of Pratylenchus brachyurus and Pratylenchus zeae associated with Brachiaria brizantha, B. decumbens and B. humidicola and their influence on forage availability and quality. The experiment was conducted in the Hisaeda Farm, Terenos, MS, Brazil. Soil, roots and plant aerial part were harvest, with ten replications each, in one square meter randomized sets encompassing three treatments: Good, Intermediary and Bad, visually characterized, considering the percentage of green material. P. brachyurus and $P$. zeae density were evaluated in soil and plant roots. Dry matter of green, dead and re-growth materials, plant nutritional status and forage quality were assessed in the aerial plant part. Soil fertility was determined in all harvested samples. Both nematode species were identified from all samples, with a larger number in the roots (between 87-311 P. brachyurus and 1-61 P. zeae. $\left.10 \mathrm{~g}^{-1}\right)$ than in the soil (0-8 P. brachyurus and 1-39 P. zeae.200 $\left.\mathrm{cm}^{-3}\right)$, however, no significant differences were found in the number of specimens between treatments. Considering that these forage species are perennial and host Pratylenchus spp, there is a tendency to increase the population of these pathogens over time, becoming a serious phytosanitary problem.

Key words: Brachiaria brizantha, B. decumbens, B. humidicola, Poaceae, Pratylenchus brachyurus, P. zeae.

\footnotetext{
Recebido para publicação em 13/07/2011 e aprovado em 03/12/2012.

Trabalho extraído da dissertação de mestrado da primeira autora. Apoio financeiro: Fundect-MS, CNPq, Unipasto e FUNDAPAM.

${ }^{2}$ Bióloga, Mestre. Laboratório de Fitopatologia, Embrapa Gado de Corte, BR 262 Km 4, Caixa Postal 154, 79002-970, Campo Grande, Mato Grosso do Sul, Brasil. Bolsista DTI/ CNPq.cassia_pgagro@hotmail.com (autora para correspondência).

${ }^{3}$ Engenheiro-Agrônomo, Doutor. Laboratório de Fitopatologia, Embrapa Gado de Corte, BR 262 Km 4, Caixa Postal 154, 79002-970, Campo Grande, Mato Grosso do Sul, Brasil. celsof@cnpgc.embrapa.br

${ }^{4}$ Engenheiro-Agrônomo, Doutor. Departamento de Fitossanidade, Universidade Estadual Paulista "Júlio de Mesquita Filho", Via de acesso Professor Paulo Donato Castellane s/ n, 14884-900, Jaboticabal, São Paulo, Brasil. jmsantos@fcav.unesp.br

${ }^{5}$ Engenheiro-Agrônomo, Doutor. Laboratório de Solos e Nutrição de Plantas, Embrapa Gado de Corte, BR 262 Km 4, Caixa Postal 154, 79002-970, Campo Grande, Mato Grosso do Sul, Brasil. macedo@cnpgc.embrapa.br
} 


\section{INTRODUÇÃO}

As pastagens cultivadas constituem a base da bovinocultura de corte no País e, dentre estas, as espécies do gênero Brachiaria têm grande importância, desde a década de 1970, pela ocupação de grandes extensões territoriais, principalmente na região dos Cerrados (Vilela et al., 2004; Macedo, 2006). Por outro lado, a competitividade e a sustentabilidade do agronegócio brasileiro, especialmente no Cerrado, têm sido seriamente ameaçadas, em virtude do aumento dos níveis populacionais e dos danos causados por nematoides do gênero Pratylenchus, em culturas de grande importância econômica e social, como soja, feijão, algodão, milho, cana-de-açúcar, além de diversas forrageiras, hortaliças e fruteiras, representando, atualmente, grave problema para diversos sistemas de produção, em várias regiões do Brasil (Goulart, 2008).

A importância econômica dos nematoides para as pastagens tem sido pouco estudada e, segundo Favoreto (2008), citando Pederson \& Quessenberry (1998), a ocorrência desses organismos em pastagens apresenta significativo impacto sobre a produção de massa e a persistência das gramíneas forrageiras. Ainda, como os produtos das pastagens não são colhidos, mas submetidos ao pastejo pelos animais, há dificuldade em determinar seu valor econômico e em quantificar as perdas de produtividade, além de isso dificultar o discernimento entre o efeito causado por nematoides e os efeitos de outros problemas, como os da pressão de pastejo, do período de seca prolongado e das demais pragas e doenças que podem acometer as raízes.

Pratylenchus spp. foram os fitonematoides mais frequentemente encontrados em associação com gramíneas e leguminosas forrageiras, em três diferentes locais da Colômbia. Destes, Pratylenchus zeae e Pratylenchus brachyurus foram comumente observados em grande número e, muitas vezes, ocorrendo em conjunto, com frequência de 30 e $40 \%$ do total de amostras coletadas, respectivamente (Stanton et al., 1989). No Brasil, Sharma et al. (2001), ao avaliarem a nematofauna associada à Brachiaria brizantha cv. Marandu, identificaram a presença de $P$. zeae em $60,9 \%$ de 64 amostras compostas de solo e raízes, coletadas em nove propriedades com problema de morte desse capim no Estado do Acre.

Evidências apontam que os fitonematoides causam reduções significativas na produtividade e na qualidade da forragem, sendo capazes de tornar as forrageiras tão sujeitas a perdas de produção quanto outras culturas (Favoreto et al. (2010), citando Bernard et al. (1998). Além destes, outros fatores, como a falta de reposição de nutrientes, podem reduzir a produtividade e, como consequência, comprometer a sustentabilidade da produção animal a pasto, por interferirem diretamente no estado nutricional das plantas e, consequentemente, na qualidade da forragem (Tarrá et al., 2010).
Informações a respeito da susceptibilidade de gramíneas forrageiras, principalmente as do gênero Brachiaria a Pratylenchus spp., são reforçadas, constantemente, na literatura (Machado et al., 2000; Sharma et al., 2001; Marchi et al. 2006; Inomoto et al., 2007; DiasArieira et al., 2009). No entanto, há escassez de trabalhos sobre os sintomas decorrentes do parasitismo e sua relação com a densidade populacional do patógeno, bem como sua associação com a degradação de pastagens.

Os objetivos deste trabalho foram determinar a densidade populacional de $P$. brachyurus e de $P$. zeae, em três espécies de Brachiaria, sob três diferentes condições da planta, bem como a sua influência na disponibilidade e qualidade da forragem.

\section{MATERIAL E MÉTODOS}

$\mathrm{O}$ trabalho foi realizado na Agropecuária Hisaeda, no município de Terenos, MS (20²0’49,3"S e 5500'24,2" W, altitude média de $249 \mathrm{~m}$ ) e nas dependências do Centro Nacional de Pesquisa Gado de Corte, unidade da Empresa Brasileira de Pesquisa Agropecuária, em Campo Grande, MS, no período de abril a agosto de 2010.

O clima da região, segundo Köppen, é de transição entre Cfa e Aw. O solo do local apresenta textura arenosa (85,78\% areia, $11,49 \%$ argila e $2,73 \%$ silte).

A área de estudo constou de três talhões, cada um medindo três hectares e apresentando uma espécie de Brachiaria, sendo estas: $B$. brizantha $\mathrm{cv}$. Marandu, $B$. decumbens $\mathrm{cv}$. Basilisk e $B$. humidicola Comum, com idades de 20, 28 e 25 anos, respectivamente. Logo após a escolha dos talhões que iriam compor a área experimental deste estudo, os animais foram retirados e somente retornaram após o término das amostragens.

A metodologia de amostragem utilizada foi a da estimativa direta da composição percentual, proposta por Whalley \& Hardy (2000), considerando-se as percentagens de material verde (MV - folhas e colmos) e material morto (MM - folhas e colmos) por $\mathrm{m}^{2}$. Sendo este um método subjetivo de seleção visual, foi realizado por três pessoas e no mesmo dia para as três espécies de braquiária. Desta forma, a pastagem foi classificada, constituindo-se os tratamentos: a) Bom (B) - $100 \times$ MV/(MV+MM) > 50\%; b) Intermediário (I) $-100 \times \mathrm{MV} /(\mathrm{MV}+\mathrm{MM})=50 \%$; c) Ruim (R) $-100 \times \mathrm{MV} /(\mathrm{MV}+\mathrm{MM})<50 \%$.

Coletaram-se dez repetições de cada tratamento, em unidades amostrais de $1 \mathrm{~m}^{2}$, que foram georreferenciadas por GPS (Sistema de Posicionamento Global), usando-se aparelho da marca Garmin ${ }^{\circ}$ MAP 76CSx.

Após a escolha dos pontos de amostragem, procedeu-se à coleta das amostras no campo, entre os meses de junho e agosto de 2010. Para tanto, utilizou-se amostrador de ferro de $1 \times 1 \mathrm{~m}$ e roçadeira Stihl ${ }^{\circledR} \mathrm{KA} 85 \mathrm{R}$. 
Toda a parte aérea da parcela foi cortada a cerca de $5 \mathrm{~cm}$ do nível do solo e pesada em dinamômetro digital Filizola ${ }^{\circledR}$ Crown DBC/DAC, obtendo-se o peso total da parcela (PTP). Posteriormente, uma subamostra foi retirada, pesada e denominada peso verde da subamostra (PVS). Em laboratório, cada subamostra foi preparada, separando-se o material verde (MV - folhas e colmos) do material morto (MM folhas e colmos). Estes foram acondicionados separadamente em sacos de papel e deixados em estufa ventilada, a $60 \pm 5{ }^{\circ} \mathrm{C}$, por 72 horas. Após esse período, as amostras foram novamente pesadas em balança digital Micronal ${ }^{\circledR}$ B2000, determinando-se a matéria seca do MV (MSMV) e do MM (MSMM), dos quais a soma determinou a matéria seca da subamostra (MSS = MSMV + MSMM), cujos valores foram a base para estimar a percentagem de material verde por $\mathrm{m}^{2}(\mathrm{PMV}=(\mathrm{MSMV} / \mathrm{MSS}) \times 100)$.

Considerando-se a baixa umidade do solo, por ausência de precipitação durante o período de execução do trabalho, foi necessária a suplementação de água, aos 20 dias após o primeiro corte. Assim, realizou-se uma única irrigação manual, com regadores plásticos, usando-se quantidade equivalente a $22 \mathrm{~mm}$ de precipitação, em cada unidade experimental.

Decorridos 40 dias do primeiro corte, realizaram-se amostragens da parte aérea (rebrota) e das raízes das plantas, como também do solo, em cada unidade experimental.

O corte da matéria verde foi realizado, conforme o procedimento utilizado na primeira amostragem, e, após o período de secagem em estufa, as amostras foram pesadas, determinando-se a matéria seca da rebrota (MSR). Posteriormente, as referidas amostras foram moídas, em moedor Marconi ${ }^{\circledR}$ tipo Willye MA-680, e levadas ao Laboratório de Nutrição de Plantas da Embrapa Gado de Corte, onde foram realizadas as análises relativas ao estado nutricional das plantas, avaliando-se os teores de fósforo $(\mathrm{P})$, cálcio $\left(\mathrm{Ca}^{+2}\right)$, magnésio $\left(\mathrm{Mg}^{+2}\right)$, potássio $(\mathrm{K})$ e enxofre (S), seguindo-se protocolo proposto por Embrapa (1999). Também, avaliou-se o valor nutritivo da forragem, quantificando-se os teores de proteína bruta (PB), fibra em detergente neutro (FB), lignina em ácido sulfúrico ( $\operatorname{LigS})$, celulose (Cel), nitrogênio total (Ntotal) e digestibilidade in vitro da matéria orgânica (DIVMO), utilizando-se a espectroscopia de reflectância do infravermelho próximo, utilizando-se o aparelho FOSS ${ }^{\circledR}$ NIRSystems mod. 5000, conforme Marten et al. (1985).

Para a coleta das amostras de solo e de raízes, utilizouse enxadão, à profundidade de $0-20 \mathrm{~cm}$, sendo cada amostra composta de cinco subamostras simples, para ambos os materiais coletados. Em laboratório, as raízes foram separadas do solo, lavadas em água corrente e, após secarem sobre papel jornal, por aproximadamente 20 minutos, foram cortadas em segmentos de aproximadamente 1 $\mathrm{cm}$ e pesadas até a quantidade de $10 \mathrm{~g}$. A seguir, foram processadas, pelo método da flotação centrífuga em solução de sacarose com caulim (Coolen \& D'Herde, 1972), para a extração dos nematoides.

O solo, após a retirada das raízes, foi homogeneizado e retirou-se uma alíquota de $200 \mathrm{~cm}^{3}$, a qual foi processada pelo método do peneiramento e flutuação centrífuga em solução de sacarose (Jenkins, 1964), para a extração dos nematoides. O restante do solo foi peneirado, acondicionado em sacos plásticos e deixados em casa de vegetação, para a secagem, durante sete dias. Após esse período, o solo foi novamente peneirado e separadas as frações para a realização da análise química, no Laboratório de Fertilidade de Solo da Embrapa Gado de Corte, onde foram avaliados os teores de cálcio $\left(\mathrm{Ca}^{+2}\right)$, magnésio $\left(\mathrm{Mg}^{+2}\right)$, fósforo $(\mathrm{P})$, potássio $(\mathrm{K})$, potencial hidrogeniônico $(\mathrm{pH})$, soma de bases $(\mathrm{SB})$, capacidade de troca catiônica (CTC), saturação por bases (V) e matéria orgânica (MO), conforme Embrapa (1997).

Após o processamento para obtenção dos nematoides, contidos no solo e nas raízes, as amostras foram colocadas em banho-maria, à temperatura de $55^{\circ} \mathrm{C}$, por cinco minutos, para inativação dos nematoides presentes, sendo, posteriormente, fixados em formalina (2\%). Para a identificação e quantificação dos referidos organismos, as amostras foram transferidas para provetas de $10 \mathrm{~mL}$ e homogeneizadas, retirando-se uma alíquota de $1 \mathrm{~mL}$, a qual foi depositada em lâmina de contagem de Peters e observada, em microscópio óptico binocular ZEIZZ ${ }^{\circledR} \mathrm{HBO}$ 50/AC. Assim, a estimativa da quantidade de espécimes de $P$. zeae (PzR) e P. brachyurus (PbR). $10 \mathrm{~g}^{-1}$ de raízes, $P$. zeae $(\mathrm{PzS})$ e $P$. brachyurus $(\mathrm{PbS}) .200 \mathrm{~cm}^{-3}$ de solo, presentes nas respectivas amostras, foi obtida por meio da multiplicação do número de nematoides (de cada espécie de Pratylenchus separadamente), presentes na lâmina de contagem de Peters, por dez (referente ao volume da proveta utilizada).

Dentre os espécimes de fitonematoides, obtidos a partir das amostras de solo e de raízes, somente $P$. brachyurus e $P$. zeae foram considerados e sua identificação foi realizada por diferenças nas características morfológicas das espécies, conforme sugerido por Gonzaga (2006).

Os resultados das análises de fertilidade do solo e do estado nutricional das plantas foram interpretados, de acordo com as tabelas de referência descritas por Sousa \& Lobato (2004) e Oliveira (2004), respectivamente.

Realizou-se análise estatística dos resultados obtidos por espécie forrageira estudada. Para este fim, os dados referentes às variáveis de nematoides $(\mathrm{PbR}, \mathrm{PzR}, \mathrm{PbS}$ e $\mathrm{PzS}$ ) foram transformados em $\sqrt{(\mathrm{x}+1)}$. Em seguida, todos os dados foram submetidos à análise de variância e, as médias dos tratamentos, comparadas pelo teste de WallerDuncan, a 5\%, utilizando-se o programa SAS versão 9.2 (SAS Institute, 2008). 


\section{RESULTADOS E DISCUSSÃO}

Analisando-se a disponibilidade de forragem no início do experimento, é possível observar que houve diferenças significativas entre os tratamentos, tendo o tratamento B apresentado as maiores médias para MSMV e PMV, em cada espécie de braquiária estudada (Tabela 1). Por outro lado, a disponibilidade de MSMM foi estatisticamente superior no tratamento ruim, em B. brizantha e $B$. decumbens, e semelhante à dos demais tratamentos, em B. humidicola.

A disponibilidade de matéria seca da parte aérea das plantas, aos 40 dias após o corte (MSR) (Tabela 1), apresentou diferença significativa entre os tratamentos apenas em $B$. decumbens, cuja produtividade máxima foi de 44,60 g.m ${ }^{-2}$. Para $B$. brizantha e $B$. humidicola, a MSR não diferiu entre os tratamentos, fato que pode estar relacionado com os teores de fósforo $(\mathrm{P})$ e potássio (K) no solo, cujos valores foram maiores em $B$. decumbens, variando entre 20,41-12,99 e 145,86-124,63 mg.dm ${ }^{-3}$, respectivamente (Tabela 2). Esses teores são considerados entre adequados e médios, para um solo com teor de argila $\leq 15 \%$, conforme proposto por Sousa \& Lobato (2004), enquanto, em B. brizantha, os teores muito baixos de P $(2,29-$ $3,88 \mathrm{mg} \mathrm{dm}^{-3}$ ) limitaram a MSR, por conta da maior exigência em $\mathrm{P}$ exibida pela espécie, em relação às demais.

Em todas as amostras de raízes, foram encontrados $P$. brachyurus e $P$. zeae (Tabela 1). Porém, os valores médios observados não diferiram, estatisticamente, entre os tratamentos, para as duas espécies de nematoides presentes nas amostras das três espécies de Brachiaria.
A espécie predominante foi $P$. brachyurus em todas as amostras de raízes, confirmando os resultados obtidos por Inomoto et al. (2007) e Machado et al. (2000), que descreveram Brachiaria spp. como susceptível a $P$. brachyurus. As populações máxima e mínima do patógeno atingiram 311 e 87 espécimes. $10 \mathrm{~g}^{-1}$ de raízes em $B$. brizantha nos tratamentos B e I, respectivamente. É importante salientar que a maior e menor densidade populacional de $P$. brachyurus foi verificada em $B$. brizantha e, embora haja grande amplitude entre esses valores, não houve diferença estatística. Isso ocorreu em virtude da variabilidade dos dados entre repetições, por causa da distribuição desuniforme desses organismos no solo (reboleiras). Ainda, em relação a $B$. brizantha, a maior população de $P$. brachyurus nas raízes foi observada no tratamento B, no qual houve a maior percentagem de material verde (PMV), 63,85\%, revelando que, embora contendo a maior densidade populacional entre todos os tratamentos, seu efeito não foi verificado na parte aérea, possivelmente, por conta do efeito compensatório, em função do intenso sistema radicular característico dessa espécie. Em B. decumbens, a maior população foi de $225 P$. brachyurus. $10 \mathrm{~g}^{-1}$ de raízes, no tratamento $\mathrm{B}$, enquanto, em B. humidicola, a maior população obtida foi de $209 P$. brachyurus, no tratamento I.

Para $P$. zeae, as médias populacionais variaram de 1 a 61 nematoides. $10 \mathrm{~g}^{-1}$ de raízes, considerando-se as três espécies de Brachiaria estudadas. Em B. humidicola, houve a menor população incidente nas raízes, cujos valores variaram de 1,9 e 6 espécimes. $10 \mathrm{~g}^{-1}$ de raízes, para os tratamentos B, I e R, respectivamente.

Tabela 1. Disponibilidades de matéria seca do material verde (MSMV) e do material morto (MSMM), percentagem de material verde (PMV), matéria seca da rebrota aos 40 dias após corte (MSR) e densidade populacional de Pratylenchus brachyurus e P. zeae em raízes (PbR e PzR) e solo (PbS e PzS), em três condições de pastagens de Brachiaria spp. (tratamento), no município de Terenos, MS

\begin{tabular}{|c|c|c|c|c|c|c|c|c|c|}
\hline \multirow[b]{2}{*}{ Espécie } & \multirow[b]{2}{*}{ Tratamento } & MSMV & MSMM & \multirow{2}{*}{$\frac{\text { PMV }}{\%}$} & \multirow{2}{*}{$\begin{array}{l}\text { MSR } \\
\text { g.m-2 }\end{array}$} & PzR & PbR & PzS & $\mathrm{PbS}$ \\
\hline & & \multicolumn{2}{|c|}{ g.m-2 ${ }^{2}$} & & & \multicolumn{2}{|c|}{$\begin{array}{c}\text { nematoides. } 10 \mathrm{~g}^{-1} \\
\text { raízes }\end{array}$} & \multicolumn{2}{|c|}{$\begin{array}{c}\text { nematoides. } 200 \mathrm{~cm}^{-3} \\
\text { solo }\end{array}$} \\
\hline \multirow{4}{*}{$\begin{array}{l}\text { Brachiaria } \\
\text { brizantha }\end{array}$} & Bom (B) & $77,68 a^{*}$ & $46,75 \mathrm{~b}$ & $63,85 \mathrm{a}$ & 26,06 a & $49 \mathrm{a}^{* *}$ & $311 \mathrm{a}^{* *}$ & $23 \mathrm{a} * *$ & $3 \mathrm{a}^{* *}$ \\
\hline & Intermediário (I) & $60,03 \mathrm{~b}$ & $65,96 \mathrm{~b}$ & $48,52 \mathrm{~b}$ & 30,99 a & $14 \mathrm{a}$ & $87 \mathrm{a}$ & $19 \mathrm{a}$ & $4 \mathrm{a}$ \\
\hline & Ruim (R) & $55,89 \mathrm{~b}$ & $95,85 \mathrm{a}$ & $37,43 \mathrm{~b}$ & $30,27 \mathrm{a}$ & $61 \mathrm{a}$ & $275 a$ & $39 a$ & $8 \mathrm{a}$ \\
\hline & $\mathrm{CV}(\%)$ & 27,32 & 35,89 & 25,80 & 55,07 & 60,23 & 54,03 & 42,19 & 74,6 \\
\hline \multirow{4}{*}{$\begin{array}{l}\text { Brachiaria } \\
\text { decumbens }\end{array}$} & Bom (B) & $56,84 \mathrm{a}$ & $54,05 \mathrm{~b}$ & $51,29 \mathrm{a}$ & $44,60 \mathrm{a}$ & $42 \mathrm{a}$ & $225 \mathrm{a}$ & $13 \mathrm{a}$ & $2 \mathrm{a}$ \\
\hline & Intermediário (I) & $34,66 \mathrm{~b}$ & $61,72 b$ & $35,02 \mathrm{~b}$ & $17,80 \mathrm{~b}$ & $51 \mathrm{a}$ & $197 \mathrm{a}$ & $15 \mathrm{a}$ & $1 \mathrm{a}$ \\
\hline & Ruim (R) & $22,16 \mathrm{c}$ & 83,11 a & $21,33 \mathrm{c}$ & $17,17 \mathrm{~b}$ & $26 \mathrm{a}$ & $134 \mathrm{a}$ & $28 \mathrm{a}$ & $1 \mathrm{a}$ \\
\hline & $\mathrm{CV}(\%)$ & 28,63 & 20,07 & 21,41 & 64,88 & 70,33 & 45,34 & 57,40 & 62,80 \\
\hline \multirow{4}{*}{$\begin{array}{l}\text { Brachiaria } \\
\text { humidicola }\end{array}$} & Bom (B) & $85,03 \mathrm{a}$ & $43,85 \mathrm{a}$ & $66,15 \mathrm{a}$ & $16,18 \mathrm{a}$ & $1 \mathrm{a}$ & $94 \mathrm{a}$ & $2 b$ & $0 \mathrm{a}$ \\
\hline & Intermediário (I) & $53,12 \mathrm{~b}$ & $42,12 \mathrm{a}$ & $56,80 \mathrm{~b}$ & $13,91 \mathrm{a}$ & $9 \mathrm{a}$ & $209 \mathrm{a}$ & $7 \mathrm{a}$ & $3 a$ \\
\hline & Ruim (R) & $54,54 \mathrm{~b}$ & $41,90 \mathrm{a}$ & $56,60 \mathrm{~b}$ & $14,89 \mathrm{a}$ & $6 \mathrm{a}$ & $193 \mathrm{a}$ & $1 \mathrm{~b}$ & $1 \mathrm{a}$ \\
\hline & $\mathrm{CV}(\%)$ & 20,88 & 32,86 & 14,71 & 34,85 & 76,83 & 39,37 & 60,76 & 59 \\
\hline
\end{tabular}

*Médias seguidas de mesma letra na coluna, para cada espécie de Brachiaria, não diferem entre si pelo teste de Waller-Duncan (p>0,05). Dados médios de dez repetições. ** Dados originais. Para fins de análise estatística, os dados foram transformados em $\sqrt{(\mathrm{x}+1)}$. CV $(\%)=$ coeficiente de variação. 
O número de espécimes de $P$. brachyurus e de $P$. zeae, entre os tratamentos, foram semelhantes, tanto nas raízes das três espécies de Brachiaria, quanto no solo (Tabela 1). Esse fato indica que, nas densidades dos patógenos observadas, não houve relação entre o parasitismo e a condição visual exibida pelas plantas, como, também, entre as variáveis relativas à disponibilidade da forragem. Fato semelhante foi observado por Sharma et al. (2001), ao avaliarem amostras compostas por $100 \mathrm{~g}$ de solo e $10 \mathrm{~g}$ de raízes de plantas sadias, plantas em estado de declínio e plantas mortas de B. brizantha cv. Marandu, no Estado do Acre. Em tais condições, esses autores obtiveram populações de $P$. zeae variando de 0 a 90,0 a 90 e 1 a 15 , respectivamente. Assim, consideraram que a morte do capim Marandu não estava relacionada com o ataque de fitonematoides e atribuíram essa baixa densidade populacional a vários fatores, entre eles, o mau crescimento e desenvolvimento das raízes, em função da compactação e da baixa fertilidade natural do solo, agravadas pela redução da matéria orgânica, ao longo dos anos, pelo pastejo contínuo e o grau de susceptibilidade da planta.

Inomoto et al. (2007), ao avaliarem a reação hospedeira de Panicum maximum e braquiárias, a dois isolados de P. brachyurus $\left(\mathrm{Pb}_{20}\right.$ e $\left.\mathrm{Pb}_{24}\right)$, observaram, em P. maximum, cultivares Tanzânia e Mombaça, as maiores densidades de nematoides nas raízes. Em braquiária, os mesmos autores identificaram, respectivamente, para as espécies $B$. brizantha, $B$. decumbens e $B$. humidicola, a presença de 21, 9 e 6, para o isolado $\mathrm{Pb}_{20}$ e 83, 44, e 7 nematoides. $\mathrm{g}^{-1} \mathrm{de}$ raiz, para o isolado $\mathrm{Pb}_{24}$.

Embora não tenha ficado clara a existência de diferenças marcantes na susceptibilidade das três espécies de
Brachiaria estudadas a $P$. brachyurus, esses resultados são parcialmente confirmados neste trabalho, pois, $B$. humidicola comportou-se como a pior hospedeira para $P$. zeae, com médias que não ultrapassaram nove espécimes. $10 \mathrm{~g}^{-1}$ de raízes (Tabela 1 ).

No solo, a espécie de nematoide predominante foi $P$. zeae, para as três espécies de Brachiaria. Apenas em $B$. humidicola, houve diferença significativa entre os tratamentos, cujas populações foram de 2, 7 e 1 nematoides. 200 $\mathrm{cm}^{-3}$, para os tratamentos B, I e R, respectivamente. Porém, esta foi a espécie de braquiária que apresentou a menor população do patógeno no solo, sendo esta considerada baixa. Para B. brizantha e B. decumbens, os tratamentos não diferiram estatisticamente, sendo que a população de $P$. zeae variou de 19 a 39 e 13 a 28, respectivamente. Quanto a $P$. brachyurus, a média populacional no solo variou de 0 a 8 , considerando-se as três espécies de braquiária, e não houve diferença significativa entre os tratamentos.

Observando-se as densidades populacionais de Pratylenchus spp. nas raízes e no solo (Tabela 1), é possível perceber que, embora estas tenham sido maiores para $P$. brachyurus nas raízes, a densidade populacional no solo foi muito baixa, enquanto, para $P$. zeae, ocorreu exatamente o inverso. Com isso, os resultados evidenciam maior preferência de $P$. brachyurus por Brachiaria spp., em relação a $P$. zeae, no entanto, eles se encontram presentes na área, sendo multiplicados nas raízes das braquiárias estudadas. Assim, há tendência ao aumento da população dos referidos patógenos, podendo se tornar um sério problema direto para as espécies forrageiras em estudo, por serem plantas perenes, ou constituírem fonte de inóculo para

Tabela 2. Resultado das análises de fertilidade das amostras de solo, coletadas em três diferentes condições de pastagens de Brachiaria spp. (tratamento), no município de Terenos, MS

\begin{tabular}{|c|c|c|c|c|c|c|c|c|c|c|}
\hline \multirow{2}{*}{ Espécie } & \multirow{2}{*}{ Tratamento } & pH & $\mathbf{C a}^{+2}$ & $\mathbf{M g}^{+2}$ & SB & CTC & $\mathbf{P}$ & $\mathbf{K}$ & $\mathbf{V}$ & MO \\
\hline & & $\mathrm{CaCl}_{2}$ & \multicolumn{4}{|c|}{$\mathrm{cmol}_{\mathrm{c}} \cdot \mathrm{dm}^{-3}$} & \multicolumn{2}{|c|}{$\mathrm{mg.dm}^{-3}$} & \multicolumn{2}{|c|}{$\%$} \\
\hline \multirow{4}{*}{$\begin{array}{l}\text { Brachiaria } \\
\text { brizantha }\end{array}$} & Bom (B) & $4,67 a^{*}$ & $0,66 \mathrm{a}$ & $0,45 \mathrm{a}$ & $1,28 \mathrm{a}$ & $4,62 \mathrm{a}$ & $3,65 \mathrm{a}$ & $66,04 \mathrm{a}$ & $27,76 \mathrm{a}$ & $2,80 \mathrm{a}$ \\
\hline & Intermediário (I) & $4,57 \mathrm{a}$ & $0,44 \mathrm{a}$ & $0,27 \mathrm{~b}$ & $0,87 \mathrm{a}$ & $3,90 \mathrm{~b}$ & $2,29 a$ & $64,92 \mathrm{a}$ & $21,88 \mathrm{a}$ & $2,25 \mathrm{~b}$ \\
\hline & Ruim (R) & $4,66 \mathrm{a}$ & $0,55 \mathrm{a}$ & $0,30 \mathrm{~b}$ & $1,04 \mathrm{a}$ & $4,16 \mathrm{ab}$ & $3,88 \mathrm{a}$ & 74,61 a & $24,11 \mathrm{a}$ & $2,44 \mathrm{ab}$ \\
\hline & $\mathrm{CV}(\%)$ & 4,20 & 50,49 & 50,34 & 40,54 & 13,90 & 54,93 & 51,64 & 33,16 & 17,71 \\
\hline \multirow{4}{*}{$\begin{array}{l}\text { Brachiaria } \\
\text { decumbens }\end{array}$} & Bom $(\mathrm{B})$ & $4,97 \mathrm{a}$ & $0,87 \mathrm{a}$ & $0,48 \mathrm{a}$ & $1,72 \mathrm{a}$ & $4,08 \mathrm{a}$ & $20,41 \mathrm{a}$ & $145,86 \mathrm{a}$ & $40,98 \mathrm{a}$ & $2,50 \mathrm{a}$ \\
\hline & Intermediário (I) & $5,09 \mathrm{a}$ & $1,05 \mathrm{a}$ & $0,55 \mathrm{a}$ & $1,87 \mathrm{a}$ & $4,25 \mathrm{a}$ & $16,49 \mathrm{a}$ & $105,59 \mathrm{a}$ & $42,94 \mathrm{a}$ & $2,63 \mathrm{a}$ \\
\hline & Ruim (R) & $5,01 \mathrm{a}$ & $0,92 \mathrm{a}$ & $0,51 \mathrm{a}$ & $1,76 \mathrm{a}$ & $4,35 \mathrm{a}$ & $12,99 \mathrm{a}$ & $124,63 \mathrm{a}$ & $40,53 \mathrm{a}$ & $2,30 \mathrm{a}$ \\
\hline & $\mathrm{CV}(\%)$ & 6,54 & 47,80 & 51,22 & 41,58 & 18,33 & 70,22 & 38,48 & 29,92 & 13,63 \\
\hline \multirow{4}{*}{$\begin{array}{l}\text { Brachiaria } \\
\text { humidicola }\end{array}$} & Bom (B) & $4,93 \mathrm{a}$ & $0,66 \mathrm{a}$ & $0,38 \mathrm{a}$ & $1,26 \mathrm{a}$ & $3,63 \mathrm{a}$ & $6,62 \mathrm{a}$ & $85,31 \mathrm{a}$ & $35,32 \mathrm{a}$ & $1,94 \mathrm{a}$ \\
\hline & Intermediário (I) & $4,87 \mathrm{a}$ & $0,78 \mathrm{a}$ & $0,36 \mathrm{a}$ & $1,33 \mathrm{a}$ & $3,54 \mathrm{a}$ & $8,27 \mathrm{a}$ & $75,85 \mathrm{a}$ & 37,17 a & $1,98 \mathrm{a}$ \\
\hline & Ruim (R) & $4,90 \mathrm{a}$ & $0,77 \mathrm{a}$ & $0,38 \mathrm{a}$ & $1,33 \mathrm{a}$ & $3,54 \mathrm{a}$ & $8,36 \mathrm{a}$ & $69,76 \mathrm{a}$ & $35,32 \mathrm{a}$ & $1,98 \mathrm{a}$ \\
\hline & $\mathrm{CV}(\%)$ & 6,16 & 45,15 & 37,77 & 35,13 & 19,13 & 77,04 & 54,58 & 28,60 & 15,98 \\
\hline
\end{tabular}

* Médias seguidas de mesma letra na coluna, para cada espécie de Brachiaria, não diferem entre si pelo teste de Waller-Duncan (p>0,05). Dados médios de dez repetições. CV $(\%)=$ coeficiente de variação. 
outras culturas, como soja, milho e outras espécies vegetais que possam vir a ser semeadas na área, em rotação ou consórcio.

Considerando-se que o principal problema, acarretado pela presença de nematoides no sistema radicular das plantas, é a interferência na translocação de água e nutrientes das raízes para a parte aérea, verificou-se o estado nutricional das plantas (Tabela 3). Foi possível observar que os níveis de $\mathrm{P}$ apenas diferiram entre os tratamentos de $B$. brizantha (3,02 a 2,68 g. $\left.\mathrm{kg}^{-1}\right)$, embora o solo, para essa espécie, tenha apresentado as menores quantidades de P (Tabela 2). No entanto, as concentrações na planta foram consideradas adequadas (0,8-3,0 g. $\left.\mathrm{kg}^{-1}\right)$, conforme a tabela de interpretação proposta por Oliveira (2004). Fato semelhante pode ser observado para as concentrações de $\mathrm{Mg}$ em $B$. decumbens, que apresentaram teores adequados no solo $\left(0,5\right.$ a $\left.2,0 \mathrm{cmolc} \mathrm{dm}^{-3}\right)$, enquanto, para $B$. brizantha e $B$. humidicola, os teores foram baixos $\left(<0,5 \mathrm{cmolc} \cdot \mathrm{dm}^{-3}\right)$ (Tabela 2). As concentrações na planta, embora adequadas (1,5-4,0 g. $\left.\mathrm{kg}^{-1}\right)$, foram menores para $B$. decumbens $\left(2,88-2,33 \mathrm{~g} \cdot \mathrm{kg}^{-1}\right)$, diferindo entre os tratamentos desta espécie (Tabela 3 ).

Quanto ao teor de K na planta (Tabela 3), houve diferença apenas para $B$. decumbens, tendo o tratamento $\mathrm{B}$ apresentado o maior teor em relação a I e R. Assim, quantidades semelhantes e acima do adequado (12-30 e 12-25 g. $\mathrm{kg}^{-1}$, respectivamente) foram observadas em $B$. brizantha e $B$. decumbens (Tabela 3), enquanto, no solo, os resultados foram considerados adequados, alto e alto, respectivamente para B. brizantha, B. decumbens e B. humidicola, levando-se em conta a CTC do solo, de acordo com Sousa \& Lobato (2004).
$\mathrm{O} \mathrm{Ca}^{+2}$ na planta diferiu apenas em $B$. decumbens, para a qual o menor valor foi observado no tratamento R, relacionado com B e I. As concentrações desse elemento foram consideradas adequadas, na planta, e baixas, no solo $\left(<1,5 \mathrm{cmol}_{\mathrm{c}} \cdot \mathrm{dm}^{-3}\right)$ para todas as espécies de braquiárias.

Considerando-se as concentrações dos elementos no solo e na planta, é possível perceber que, nas densidades populacionais observadas, a infestação de Pratylenchus spp. não interferiu na translocação de nutrientes das raízes para a parte aérea.

De acordo com Oliveira (2004), nem sempre é possível encontrar estreitas correlações entre as concentrações dos nutrientes, no solo, com aquelas encontradas nas folhas, por causa do emprego de soluções extratoras nas análises de solo (ácidos diluídos, sais, água quente, resina), cujas condições não refletem aquelas observadas em condições de campo, enquanto, na análise do material vegetal são quantificados os teores totais dos nutrientes absorvidos pelas plantas. Porém, o autor considera que as duas análises são complementares, para a solução de problemas nutricionais.

Quanto aos caracteres relativos à qualidade da forragem de folhas e colmos (Tabela 4), houve diferença entre os tratamentos de B. decumbens, tendo o tratamento B apresentado maiores quantidades de PB, Ntotal e DIVMO e os menores valores para FDN e Cel, demonstrando o melhor valor nutritivo, em relação aos demais tratamentos dessa espécie (Tabela 4). Porém, como não houve diferença significativa na densidade populacional de $P$. brachyurus e $P$. zeae, entre os tratamentos de $B$. decumbens (Tabela 1), infere-se que a quantidade de espécimes observada não foi suficiente para reduzir a qualidade da forragem.

Tabela 3. Resultado das análises de macronutrientes contidos na parte aérea da rebrota de plantas, coletadas em três diferentes condições de pastagens de Brachiaria spp. (tratamento), no município de Terenos, MS

\begin{tabular}{|c|c|c|c|c|c|c|}
\hline \multirow{2}{*}{ Espécie } & \multirow{2}{*}{ Tratamento } & $\mathbf{P}$ & $\mathrm{Ca}^{+2}$ & $\mathbf{M g}^{+2}$ & $\mathbf{K}$ & $\mathbf{S}$ \\
\hline & & \multicolumn{5}{|c|}{ g.kg ${ }^{-1}$} \\
\hline \multirow{4}{*}{ B. brizantha } & Bom (B) & $3,02 \mathrm{a}^{*}$ & $3,28 \mathrm{a}$ & $3,46 \mathrm{a}$ & $36,80 \mathrm{a}$ & $2,41 \mathrm{a}$ \\
\hline & Intermediário (I) & $2,68 \mathrm{~b}$ & $3,04 \mathrm{a}$ & $3,12 \mathrm{a}$ & $34,72 \mathrm{a}$ & $2,31 \mathrm{a}$ \\
\hline & Ruim (R) & $2,71 \mathrm{~b}$ & $3,01 \mathrm{a}$ & $3,20 \mathrm{a}$ & $33,85 \mathrm{a}$ & $2,34 \mathrm{a}$ \\
\hline & CV $(\%)$ & 10,45 & 19,45 & 14,18 & 15,94 & 7,34 \\
\hline \multirow{4}{*}{ B. decumbens } & Bom (B) & $3,18 \mathrm{a}$ & $4,02 \mathrm{a}$ & $2,88 \mathrm{a}$ & $36,80 \mathrm{a}$ & $2,51 \mathrm{a}$ \\
\hline & Intermediário (I) & $3,30 \mathrm{a}$ & $3,77 \mathrm{a}$ & $2,68 \mathrm{a}$ & $33,92 \mathrm{~b}$ & $2,43 \mathrm{a}$ \\
\hline & Ruim (R) & $3,09 \mathrm{a}$ & $3,07 \mathrm{~b}$ & $2,33 \mathrm{~b}$ & $33,13 \mathrm{~b}$ & $2,35 \mathrm{a}$ \\
\hline & $\mathrm{CV}(\%)$ & 17,83 & 18,78 & 12,20 & 8,65 & 7,08 \\
\hline \multirow{4}{*}{ B. humidicola } & Bom (B) & $2,59 \mathrm{a}$ & $3,59 \mathrm{a}$ & $3,28 \mathrm{a}$ & $19,05 \mathrm{a}$ & $2,21 \mathrm{a}$ \\
\hline & Intermediário (I) & $2,71 \mathrm{a}$ & $3,45 \mathrm{a}$ & $3,98 \mathrm{a}$ & $19,51 \mathrm{a}$ & $2,11 \mathrm{a}$ \\
\hline & Ruim (R) & $2,61 \mathrm{a}$ & $3,59 \mathrm{a}$ & $3,11 \mathrm{a}$ & 18,39 a & $2,09 \mathrm{a}$ \\
\hline & $\mathrm{CV}(\%)$ & 17,58 & 17,54 & 18,71 & 28,77 & 6,00 \\
\hline
\end{tabular}

* Médias seguidas de mesma letra na coluna, para cada espécie de Brachiaria, não diferem entre si pelo teste de Waller-Duncan (p>0,05). Dados médios de dez repetições. CV $(\%)=$ coeficiente de variação. 
Tabela 4. Percentagem de proteína bruta (PB), fibra em detergente neutro (FDN) lignina sulfúrica (LigS), celulose (Cel) nitrogênio total (Ntotal) e digestibilidade in vitro da matéria orgânica (DIVMO), na matéria seca da rebrota de Brachiaria spp., coletadas em três diferentes condições de pastagem (tratamento), no município de Terenos, MS

\begin{tabular}{|c|c|c|c|c|c|c|c|}
\hline \multirow{2}{*}{ Espécie } & \multirow{2}{*}{ Tratamento } & PB & FDN & LigS & Cel & Ntotal & DIVMO \\
\hline & & \multicolumn{6}{|c|}{$\%$} \\
\hline \multirow{4}{*}{ B. brizantha } & Bom (B) & $17,11 a^{*}$ & $83,14 a$ & $3,58 \mathrm{a}$ & $25,29 \mathrm{ab}$ & $2,74 \mathrm{a}$ & $79,98 \mathrm{a}$ \\
\hline & Intermediário (I) & $15,69 \mathrm{a}$ & $84,34 \mathrm{a}$ & $3,49 a$ & $26,46 a$ & $2,51 \mathrm{a}$ & $77,61 \mathrm{a}$ \\
\hline & Ruim (R) & $17,24 \mathrm{a}$ & $81,96 a$ & $3,34 \mathrm{a}$ & $24,96 \mathrm{~b}$ & $2,76 \mathrm{a}$ & $82,99 a$ \\
\hline & $\mathrm{CV}(\%)$ & 9,63 & 2,90 & 11,57 & 5,62 & 9,61 & 8,06 \\
\hline \multirow{4}{*}{ B. decumbens } & Bom (B) & $17,66 \mathrm{a}$ & $72,35 \mathrm{c}$ & $2,38 \mathrm{a}$ & $20,13 b$ & $2,83 a$ & $85,85 \mathrm{a}$ \\
\hline & Intermediário (I) & $15,97 \mathrm{~b}$ & $74,49 \mathrm{~b}$ & $2,53 \mathrm{a}$ & $20,69 a b$ & $2,55 b$ & $79,98 b$ \\
\hline & Ruim (R) & $15,93 b$ & $79,73 a$ & $2,65 \mathrm{a}$ & $21,69 \mathrm{a}$ & $2,55 \mathrm{~b}$ & $79,86 b$ \\
\hline & $\mathrm{CV}(\%)$ & 10,40 & 3,32 & 12,49 & 5,53 & 10,42 & 5,87 \\
\hline \multirow{4}{*}{ B. humidicola } & Bom (B) & $14,60 \mathrm{a}$ & $77,72 \mathrm{a}$ & $2,33 \mathrm{a}$ & $24,48 \mathrm{a}$ & $2,34 \mathrm{a}$ & $75,88 \mathrm{a}$ \\
\hline & Intermediário (I) & $14,41 \mathrm{a}$ & $78,65 \mathrm{a}$ & $2,42 \mathrm{a}$ & $24,45 \mathrm{a}$ & $2,31 \mathrm{a}$ & $73,60 \mathrm{a}$ \\
\hline & Ruim (R) & $15,01 \mathrm{a}$ & $76,16 \mathrm{a}$ & $2,24 \mathrm{a}$ & $23,33 \mathrm{a}$ & $2,40 \mathrm{a}$ & $75,17 \mathrm{a}$ \\
\hline & $\mathrm{CV}(\%)$ & 6,71 & 3,88 & 12,89 & 6,01 & 6,75 & 5,12 \\
\hline
\end{tabular}

*Médias seguidas de mesma letra na coluna, para cada espécie de Brachiaria, não diferem entre si pelo teste de Waller-Duncan ( $>0,05)$. Dados médios de dez repetições. CV $(\%)$ = coeficiente de variação.

\section{CONCLUSÕES}

Nas condições experimentais, as diferenças observadas na condição visual da pastagem não estão relacionadas com a infestação de espécies de Pratylenchus na área, e sim com a fertilidade do solo, para $B$. brizantha, com estado nutricional da planta, $B$. decumbens, enquanto, para $B$. humidicola, outros fatores bióticos ou abióticos, não avaliados neste trabalho, devem estar envolvidos nas diferenças entre os tratamentos.

Considerando-se que Brachiaria brizantha, $B$. decumbens e $B$. humidicola são perenes e hospedam $P$. brachyurus e $P$. zeae, há tendência ao aumento da população desses patógenos ao longo do tempo, podendo se tornar um sério problema fitossanitário.

\section{AGRADECIMENTOS}

À Fundect-MS e ao CNPq, pela concessão das bolsas de mestrado e DTI, respectivamente, e à Unipasto e FUNDAPAM, pelo apoio financeiro. À Katyuce da S. Chermouth, à Margareth V. Batista, a Francisco A. Quetez, a Marcelo José da Silva, à Vanessa C. P. de Araújo, à Carolina de A. Queiróz, a Guilherme Mallmann, a Paulino G. Gomes e Clodoaldo O. de Souza, pelo auxílio na condução do experimento.

\section{REFERÊNCIAS}

Coolen WA \& D'Herde CJ (1972) A method for the quantitative extraction of nematodes from plant tissue. Ghent, State Nematology and Entomology Research Station. 77p.

Dias-Arieira CR, Ferraz S \& Ribeiro RCF (2009) Reação de gramíneas forrageiras a Pratylenchus brachyurus. Nematologia Brasileira, 33:90-93.
Empresa Brasileira de Pesquisa Agropecuária - Embrapa (1999) Manual de análises químicas de solos, plantas e fertilizantes. Brasília, Embrapa Comunicação para Transferência de Tecnologia. 370p.

Empresa Brasileira de Pesquisa Agropecuária - Embrapa (1997) Centro Nacional de Pesquisa de Solos. Manual de métodos de análises de solo. $2^{\mathrm{a}}$ ed. Rio de Janeiro, Embrapa Solos. 212p.

Favoreto L, Santos JM, Calzavara AS, Barbosa JC \& Lara LA (2010) Estudo do processo de infecção de sementes de Brachiaria brizantha por espécies de Aphelenchoides e de tratamentos para o controle desses nematoides. Nematologia Brasileira, 34:10-17.

Favoreto L (2008) Taxonomia, interação patógeno-hospedeiro, estudo fitossanitário e denematização de sementes de gramíneas forrageiras. Tese de Doutorado. Universidade Estadual Paulista, Jaboticabal. 53p.

Gonzaga V (2006) Caracterização morfológica, morfométrica e multiplicação in vitro das seis espécies mais comuns de Pratylenchus Filipjev, 1936 que ocorrem no Brasil. Tese de Doutorado. Universidade Estadual Paulista, Jaboticabal. $79 \mathrm{p}$.

Goulart AMC (2008) Aspectos gerais sobre nematóides-das-lesões-radiculares (gênero Pratylenchus). Planaltina, Embrapa Cerrados. $27 \mathrm{p}$.

Inomoto MM, Machado ACZ \& Antedomênico SR (2007) Reação de Brachiaria spp. e Panicum maximum a Pratylenchus brachyurus. Fitopatologia Brasileira, 32:341-344.

Jenkins WR (1964) A rapid centrifugal-flotation technique for separation nematodes from soil. Plant Disease Reporter, 48:692695.

Macedo MCM (2006) Aspectos edáficos relacionados com a produção de Brachiaria brizantha cultivar Marandu. In: Barbosa RA (Ed.) Morte de pastos de braquiárias. Campo Grande, Embrapa Gado de Corte. p.35-65.

Machado ACZ, Venzke Filho SP \& Inomoto MM (2000) Reprodução de fitonematóides identificados em uma área de plantio direto em três espécies de gramíneas. Nematologia Brasileira, 24:173-177.

Rev. Ceres, Viçosa, v. 60, n.1, p. 030-037, jan/fev, 2013 
Marchi CE, Fernandes CD, Santos JM, Jerba VF \& Bueno ML (2006) Nematóides associados às pastagens de capim-marandu em declínio em regiões de Mato Grosso e Rondônia. In: 43 Reunião Anual da Sociedade Brasileira de Zootecnia, João Pessoa. Anais, SBZ. CD-ROM.

Marten GC, Shenk JS \& Barton FE (1985) Near infrared reflectance spectroscopy (NIRS): analysis of forage quality. Washington, USDA. $110 \mathrm{p}$

Oliveira AS (2004) Análise foliar. In: Sousa DMG \& Lobato E (Eds.) Cerrado - correção do solo e adubação. Brasília, Embrapa Informação Tecnológica. p.245-255.

SAS Institute Inc. (2008) SAS/STAT® 9.2 User's Guide. Cary, SAS Institute Inc. 202p.

Sharma RD, Cavalcante MJB \& Valentim JF (2001) Nematóides associados ao capim Brachiaria brizantha cv. Marandu no Estado do Acre, Brasil. Nematologia Brasileira, 25:217-222.

Sousa DMG \& Lobato E (2004) Anexos. In: Sousa DMG \& Lobato E (Eds.) Cerrado - correção do solo e adubação. Brasília, Embrapa Informação Tecnológica. p.385-416.
Stanton JM, Siddiqi MR \& Lenné JM (1989) Plant-parasitic nematodes associated with tropical pastures in Colombia. Nematropica, 19:169-175.

Tarrá ILC, Luizão FJ, Wandelli EV, Teixeira WG, Morais WJ \& Castro JGD (2010) Tempo de uso em pastagens e volume dos macroporos do solo na Amazônia Central. Revista Brasileira de Engenharia Agrícola Ambiental, 14:678-683.

Vilela L, Soares WV, Sousa DMG \& Macedo MCM (2004) Calagem e adubação para pastagens. In: Sousa DMG \& Lobato E (Eds.) Cerrado - correção do solo e adubação. Brasília, Embrapa Informação Tecnológica. p.367-382.

Whalley RDB \& Hardy MB (2000) Measuring Botanical Composition of Grasslands. In: Mannetje LT \& Jones RM (Eds.) Field and laboratory methods for grassland and animal production research. Cambridge, CABI. p.67-102. 